\title{
HISTORIA Y PUNICIÓN: ÁNGEL VALBUENA PRAT, DEPURADO*
}

\author{
ENRIQUE SERRANO ASENJO \\ Universidad de Zaragoza
}

\author{
Entre el estruendo ronco de máquinas de infierno \\ cuando ciudad y campo llenan sangre y terror, \\ y vendavales ciegos parten casas y cúspides \\ en ruinas de dolor sobrenadando el hombre \\ parece que se borra la vibración del ángel. \\ «Voz de paz en la guerra», Barcelona, 3-3-1938
}

\section{RESUMEN}

El artículo analiza el expediente de depuración del catedrático e historiador de la literatura don Ángel Valbuena Prat. Valbuena fue trasladado forzosamente desde su puesto en la Facultad de Filosofía y Letras de Barcelona a la de Murcia en 1943. La motivación de este acto administrativo se basó principalmente en determinados aspectos de su Historia de la literatura española (Barcelona, 1937). El interés del trabajo procede no sólo de la información que aporta sobre la represión de la dictadura franquista en el ámbito universitario, sino también de los datos que se proporcionan en torno a la recepción e historia de uno de nuestros textos de historiografía literaria de mayor prestigio a lo largo del siglo Xx.

Palabras clave: Ángel Valbuena Prat; Historiografía de la Literatura Española; Depuración franquista.

\begin{abstract}
The present article delves into the purge file on the Professor and literaty historian Ángel Valbuena Prat. In 1943, Valbuena was forcefully removed from his teaching post at the Faculty of Arts in Barcelona and sent to that in Murcia. This administrative measure was mainly motivated by certain aspects of his Historia de la literatura española (A History of Spanish Literature; Barcelona, 1937). The analysis carried out in what follows throws light on how the repression enforced by Franco's dictatorship affected the university life of the period, while simultaneously providing information on the reception and history of one of our most prestigious works of literary historiography in the 20th century.
\end{abstract}

Key words: Ángel Valbuena Prat; Historiography of Spanish Literature; Franco's Purge.

* El presente trabajo se enmarca en el proyecto de investigación BFF2002-03401 del Ministerio de Educación y Cultura. 
El profesor Ángel Valbuena Prat, catedrático de Lengua y Literatura Españolas de la Facultad de Filosofía y Letras de la Universidad de Barcelona, fue trasladado forzosamente a la de Murcia por Orden del Ministerio de Educación Nacional fechada el 21 de enero de 1943 (B. O. E. 3 de febrero). Era el resultado último de su expediente de depuración y llevaba el añadido de que no se le permitía solicitar cátedras vacantes durante cinco años $^{1}$. Para apreciar adecuadamente la magnitud del castigo se ha de tener en cuenta que Valbuena pasaba de una gran universidad a otra mucho más pequeña, con el rasgo estructural desde su fundación en 1915 de tratarse de una universidad de paso y dirigida a la sazón por el rector Jesús Mérida Pérez, futuro obispo de Astorga, que le imprime desde 1939 una orientación sobre todo autoritaria y eclesiástica (Nicolás Marín, 1991: 345).

Lo menos malo de la sentencia consiste en que a partir de la resolución del mencionado expediente el encausado podría volver a recibir su sueldo íntegro, pues desde la incoación del mismo en febrero de 1940, como disponía la Orden de 2 de junio de 1939 (B. O. E. 4 de junio), tan sólo percibía el $50 \%$ de la paga. Además, en cierto modo no salía tan mal librado, porque las sanciones previstas por la ley de 10 de febrero del 39 (B. O. E. 14 de febrero), que fijaba las normas para la depuración de funcionarios públicos, formaban una serie desde la menor, que es la que recae sobre Valbuena Prat $^{2}$, hasta la máxima pena, a saber, la separación definitiva del servicio. Precisamente eso era lo solicitado por el juez instructor de su expediente, Francisco Gómez del Campillo, catedrático de Derecho Canónico y rector de la Universidad de Barcelona entre julio de 1941 y febrero de 1945 .

A indagar en algunos de los detalles que rodean esta peripecia vital de don Ángel Valbuena se dedica mi trabajo, porque, como veremos, en realidad lo que está en la picota es una de las obras mayores de la historiografía literaria española (Palomo y Prieto, 2000; Pozuelo Yvancos, 2000), la Historia de la literatura española que nuestro autor había publicado por primera vez en 1937. La situación a la que nos vamos a enfrentar sólo se entiende si partimos de un entorno social degradado en extremo, miserable y envilecido (Gracia, 2001: 17), entorno en el que la institución universitaria pasa por una etapa de «fascismo clerical» (Ruiz Carnicer, 2001: 169). El caso es que uno de los aspectos fundamentales de la actividad del Ministerio de Educación en los primeros años cuarenta fue la depuración del personal docente (cfr. Alted Vigil, 1991: 113 ss.; Ruiz Carnicer, 2001: 169).

1 Toda la documentación citada, salvo indicación en contra, está tomada del expediente personal de Valbuena en el Archivo General de la Administración, en Alcalá de Henares, Sección Educación, legajo 20.317.

2 Más precisamente el texto legal reza: «Traslado forzoso, con prohibición de solicitar cargos vacantes durante un período de uno a cinco años». 
Desde su memoria, imprescindible para esa edad, Pedro Laín Entralgo testifica que: «continuó implacable tal "depuración" y deliberada y sistemáticamente se prescindió de los mejores, si estos parecían ser mínimamente sospechosos de liberalismo o republicanismo, o si por debajo de su nivel había candidatos a un tiempo derechistas y ambiciosos» (1989: 287).

Los argumentos que el juez instructor Francisco Gómez esgrimió en su propuesta de separación definitiva del escalafón de Valbuena, fechada el 8 de octubre de 1940, fundamentalmente se basaban en un par de notas incluidas en dos textos publicados durante el conflicto civil: una en su Historia de la poesía canaria, volumen I, publicada por el Seminario de Estudios Hispánicos de la Universidad de Barcelona en 1937; y la otra en el volumen II de la mencionada Historia de la literatura. La primera nota decía en torno a la desaparición del poeta Luis Rodríguez de Figueroa: «En la guerra actual -1936-, de las noticias que poseemos se desprende que ha sido fusilado por los rebeldes, en tierras de Canarias; hecho lamentable que habría que añadir a la serie que culmina en la muerte del gran Federico García Lorca» (1937b: 114, n. 2). Sebastián de la Nuez recuerda que la obra hubo de ser recogida por este motivo (1978: 205).

La segunda nota atañe a Lorca precisamente: «Indicamos la fecha de muerte, ya que todas las noticias que hasta ahora se poseen, tristemente no rectificadas, declaran su dramático fin, en la actual guerra española, fusilado por los rebeldes en tierras de Granada en agosto de 1936» (1937a, II: 924 , n. 2). No todos los ejemplares de ese volumen segundo de la Historia de la literatura española de Valbuena reproducen el texto indicado. Hay otro estado de edición posterior en el que se ha desplazado la llamada de la nota desde el año de la muerte al final de la frase que sigue: «FEDERICO GARCía LORCA, el granadino (1898-1936) [aquí se ubicaba la llamada de la nota en el primer estado], el poeta que ha adquirido una mayor resonancia de público y entusiasmo en la nueva literatura.» Pues bien, al pie de esa página y a modo de extraña aclaración al influjo aludido de la producción lorquiana, se lee: «Su Romancero gitano influyó en el Romancero carnal de N. SANZ Y RUIZ DE LA PeÑa. Este poeta continúa la buena tradición de los escritores de Valladolid, afianzando su personalidad en sus intensos Romances de guerra y amor, de excelente musicalidad y riqueza de imágenes» ${ }^{3}$.

La sustitución de la muy comprometedora nota original por la referencia a un escritor de segunda fila, hoy perfectamente olvidado, pero afecto al régimen, permitió que el conjunto de la obra continuase su difusión. La anécdota, tan significativa del sino de los tiempos, la ha contado el editor

\footnotetext{
${ }^{3}$ Los ejemplares consultados con la nota de la muerte de Lorca pertenecen a las Universidades Autónoma de Barcelona, de Gerona y Pompeu Fabra. Los que presentan la nueva nota pertenecen a la Universidad Complutense, a la de Zaragoza y a la Biblioteca de Catalunya.
} 
Gustavo Gili en escrito de 3 de octubre de 1940 que Valbuena adjuntaba a su contestación al pliego de cargos del juez depurador ${ }^{4}$ : «En la actualidad, y de acuerdo con la Jefatura Nacional de Prensa y Propaganda, se convino substituir el medio pliego en que figura la nota aludida, forma en que se continúa vendiendo tan magna obra con el beneplácito de muchas personalidades del Movimiento Nacional.» Quedaba en pie, no obstante, la razón de ser del texto primero y a ello también acudía Gili, como el propio Valbuena Prat en su contestación a Gómez del Campillo. Uno y otro lo explican por la presión de las circunstancias o, en otros términos, por las coacciones ejercidas sobre las actividades literarias en la «España roja» (sic).

Pero el juez no estimó tales presiones como eximente, ni como atenuante siquiera, y argumentaba con fanatismo para pedir la sanción máxima:

\begin{abstract}
pues sería verdaderamente dañoso para los intereses de la Patria y el prestigio de la Universidad, el mantenimiento en sus cátedras a personas de tan peligroso conformismo y aquiescencias, cuando precisamente lo que requiere nuestro Glorioso Movimiento y la nueva España es firmeza de criterio y valor cívico para no apostatar en ningún caso. Si estas conductas conformistas hubieran predominado en España, el régimen rojo-separatista hubiera triunfado.
\end{abstract}

Que no se siguiera la recomendación punitiva de Gómez del Campillo no quiere decir que se olvidaran consideraciones tan leales al Movimiento como las expuestas, que no debieron ser excepcionales en el personaje, para su futuro profesional. De cualquier modo, el depurador aportaba otros elementos de menor peso que los citados para sustentar su propuesta..

Para empezar remite a la percepción de Felipe II que propone Valbuena en la Historia de la literatura española y de la que Gómez entresaca los pasajes siguientes: «monarca pálido y chiquito», «fue la parte menos honda y más oficial del momento5: el jesuitismo, la burocracia, algo de una mala fe poco gallarda», «deja mucho que desear en punto a conducta. Y no nos referimos al exceso de celo en la represión religiosa, que constituyó mucho tiempo el blanco de las diatribas contra el rey (...) Con los hechos históricos, ajenos a la cuestión religiosa, hay suficiente para que el rey del rosario y el vestido negro tenga un cierto matiz de Tartuffe» $\mathrm{y}$ «hace pensar en el retrato de Pantoja de la Cruz en que Felipe II, lívido de rostro y con negras vestiduras, pasa los dedos por las cuentas del rosario. Detrás estaban las caras de la princesa de Éboli, Antonio Pérez y el Justi-

\footnotetext{
${ }^{4}$ El pliego de cargos de Gómez del Campillo tiene fecha 30 de septiembre, a continuación Valbuena tenía un plazo de ocho días para contestar, y lo hizo el 5 de octubre. Por fin, como ya se dijo, la propuesta al Ministro, que era quien tomaba la decisión final, lleva fecha de 8 de octubre del año 40.

${ }^{5}$ En realidad Valbuena redactó con mayor ductilidad: «fue más bien la parte menos honda».
} 
cia de Aragón ${ }^{6}$. Lo dicho es bastante para acusar al historiador de tener «un sentimiento de aversión a nuestras glorias nacionales y una calurosa participación en los postulados de la leyenda negra». El juez mentía.

La acusación, para la que no se facilitan más datos que esos fragmentos aislados y no figuraba en el pliego de cargos inicial, por lo que Valbuena no se pudo defender de la misma, tenía una evidente mala fe. Y no sólo porque nuestro investigador fuese una autoridad en la cultura de los Siglos de Oro desde sus primeras incursiones académicas en torno a Calderón y sus autos sacramentales, de forma que nos hallamos ante un profundo conocedor de la época. Lo que hace más flagrante la intención aviesa del juez depurador es el planteamiento mismo que tiene Valbuena Prat de la época de Felipe II bien ajeno a cualquier leyenda negra y que antecede unas pocas líneas a los primeros pasajes reproducidos al respecto: «El sedimento de tradiciones, el incremento de los valores esenciales españoles, especialmente el sentimiento y pensamiento religiosos, incluso el mismo cierre del imperio a las luchas y divisiones de la Europa de la segunda mitad del siglo XVI, formaron una unidad, una cultura, una línea de conducta» (1937a, I: 479). El crítico continuaba explicando que aún entonces se abordaba el periodo «con la pasión del fanático o del sectario, o con la ingenua desorientación del ignorante». Lo que no podía saber es que precisamente con una mezcla de todo ello se iba a leer su trabajo.

Como cargo final en contra, la propuesta del expediente señalaba a la supuesta ideología izquierdista de Valbuena, según se deducía de su tratamiento del erasmismo, la llamada generación del 98 y la literatura posterior, con mención expresa de Lorca y Alberti, mas ya sin citas textuales en ninguno de los casos. Vale la pena reparar en qué pudo atraer la atención del acusador en cada uno de estos apartados de la Historia en cuestión. Alicia Alted ha indicado que los principios ideológicos del estado en formación fueron «el sentido religioso católico y el sentimiento nacional de unidad» (1991: 96). Y el ponderado enfoque que Ángel Valbuena planteaba sobre la recepción de Erasmo de Roterdam en España meditaba sobre ambos pilares: «creemos que es una visión negativa y noventayochista el lamentar el corte con los discípulos de Erasmo, o el añorar una España en la Edad de Oro protestantizante y dividida. Tampoco sería exacto lamentar el hecho del erasmismo» (1937a, I: 364).

En el momento de afirmación del nuevo estado contrarrevolucionario hacer un relato del pasado con afirmaciones como «España estuvo a un paso de una separación de la catolicidad» (366), por más que se rodeasen de un discurso verdaderamente reflexivo o quizá por eso mismo, a la fuer-

${ }^{6}$ La frase final aparece algo distinta en el texto de Valbuena: «Detrás de esto, estaban los casos de la princesa». Las citas se pueden ubicar en la Historia de la literatura española, 1937a, I: 479, 480, 490 y 613, respectivamente. 
za hubo de despertar sospechas en lectores radicales, como sin duda fue Francisco Gómez. Y es que, además del contenido, a mi ver, en la perspectiva de Valbuena respecto del tema indicado hay un componente más formal que es difícilmente compatible con el espíritu postbélico; es decir, como buen historiador, el profesor barcelonés se esfuerza por comprender el pasado y ello implica que su construcción verbal y conceptual alrededor de la Historia resulta flexible, matizada, en absoluto maniquea, ni proselitista. Opta por un relato de la complejidad y no de la simplicidad propagandística, como prefería el ideario triunfal ${ }^{7}$.

Por lo que respecta al 98, prosiguen las mentiras de Gómez del Campillo cuando esgrime la «simpatía por el pesimismo derrotista de "los del 98"». En efecto, del criticismo de Unamuno, Baroja y compañía, Valbuena Prat sobre todo destaca su sentido revalorizador y creativo. Y desde luego no se percibe simpatía alguna cuando hace constar que: «Como en otros momentos comparables de desaliento nacional, con ser muy dolorosa la realidad, aún se hizo mayor en las mentes y los labios desesperanzados. El español hizo una vez más trofeos de su propia miseria, y su crítica de los valores raciales fue negativa y doliente» (1937a, II: 836). Pero una lectura atenta de la exposición y las conclusiones del instructor descubre que estos detalles resultan por completo irrelevantes, pues parte en buena medida de prejuicios sin pretender justipreciar el alcance de la labor historiográfica del autor.

Más aún, como resulta obvio de lo visto hasta el momento, se busca ante todo la condena y no la ecuanimidad. No importa tampoco, claro, que en la detenida presentación de la obra de García Lorca en absoluto se remita a cuestiones sociales o políticas, con la salvedad de la nota referida, ni siquiera al comentar el «Romance de la Guardia Civil española». Y algo similar podría decirse de la presencia del nombre de Rafael Alberti como baza postrera de la acusación. Desde luego el autor de Cal y canto figura con un alto rango en el canon propuesto por el historiador, como el propio Lorca (cfr. Díez de Revenga, 2000), pero lo que Valbuena más aprecia en él no es precisamente su obra de compromiso político. Dedica un epígrafe a Sobre los ángeles y en cuanto a su viraje ideológico de los años treinta advierte:

Desde 1931 comienza una etapa de versos de ideario y propaganda comunistas: «al servicio de la revolución española y del proletariado universal». «Consignas» y los otros ejemplos de esta clase de poesía nos parecen, literariamente, algo todavía vacilante, sin hondas raíces poéticas, más un camino que una

${ }^{7}$ Sirva esta cita como prueba añadida: «Está muy bien el erasmismo en tiempo de Carlos V, y también lo está la reacción católica en España en el reinado siguiente. Las dos posiciones contribuyen a un todo armónico, que se explica y se complementa, sin que lo primero llegue a estorbar la línea recta de una cultura que se dio en el momento más maduro con valores esencialmente católicos» (1937a, I: 364). 
meta a la que no ha llegado ni aun en los más recientes ejemplos emocionados que conocemos. (1937a, II: 942).

Y va más lejos todavía al dar noticia del teatro albertiano, pues opina «que el circunstancial "Fermín Galán" es literariamente una equivocación» (971).

No resulta fácil valorar las razones o convicciones últimas de Francisco Gómez del Campillo al actuar como lo hizo, pero sin duda vio en Valbuena a un enemigo y acaso un escalón de su carrera académica. Tampoco nuestro objetivo atañe a ese particular. Sí tenemos elementos de juicio para reparar en la relación del historiador con su obra magna y aquí debe constar su defensa emocionada en la contestación al pliego de cargos, que no descuidaba la mención de ciertos nombres que pudiesen servir de aval del libro:

el que suscribe cree haber llevado a cabo una labor que le enorgullece en dicha Historia de la literatura fruto del trabajo de toda una vida, y cuyo españolismo ha merecido elogios de personas tan conspicuas en el Movimiento como los polígrafos P. Justo Pérez de Urbel, y P. Félix García, el catedrático Entrambasaguas, los poetas Luis Rosales y Luis Felipe Vivanco, entre muchísimos otros críticos y escritores actuales.

Más firmas concurrían en los documentos adjuntos a la contestación como apoyos de la misma: Allison Peers y Alexander A. Parker declaraban que las conferencias impartidas por Valbuena en Inglaterra durante la guerra versaron exclusivamente de temas literarios; José María Castro y Calvo, profesor de la Universidad de Zaragoza perseguido por «los rojos» (sic), da testimonio de la ayuda moral y material que le prestó don Ángel; y hasta se recogen dos cartas de Pedro Laín, pidiéndole colaboraciones para Escorial, entre otros asuntos de re litteraria.

La autodefensa del profesor expedientado reúne firmas, pero también títulos de la propia tarea intelectual: el agónico y muy trabajado en lo formal Dios sobre la muerte. Poemas. Soliloquio a través de una vida 19141939 A. V. (1939), el ensayo titulado El sentido católico en la literatura española ${ }^{8}$, las ediciones de Autos sacramentales y El gran teatro del mundo de Calderón, así como su Antología de la poesía sacra española (1940; cfr. Díez de Revenga, 1977). Pilar Palomo ha recordado que al final de su trayectoria Valbuena se definía como prototipo del homo religiosus una-

\footnotetext{
${ }^{8}$ En este volumen, tan ligado a las circunstancias personales y colectivas, pueden leerse consideraciones como: «Una de las más grandes adquisiciones para el alma española del siglo XX es la conciencia de su catolicidad. En todo el panorama ideológico se acusa el nuevo sentido de la valoración de la cultura católica» (1940: 3); o bien: «la decadencia de las letras coincide con las oleadas de descatolización, hasta llegar, por la vía del desaliento y la angustia, a recobrarse España y religión, catolicismo y patria, unidad de cultura y unidad de fe, en los momentos decisivos que culminan en la reconstrucción nacional del momento presente./ El presente libro trata de ser sencillamente una aportación a esta labor de todos los españoles conscientes» (4).
} 
muniano y subraya el importante papel que la contienda civil jugó en su vivencia de la religión (Palomo y Prieto, 2000: 23). De todas las formas, según se vio y al menos en un principio, tan persuasiva argumentación no le sirvió de mucho; y aunque, al llegar la resolución de su caso en 1943, el ministro Ibáñez Martín rebajó el castigo, todo lo anterior no evitó el destierro'.

Hay que dejar constancia, no obstante, de que Valbuena no cejó en el empeño de reivindicar su contribución mayor al conocimiento de nuestra historia literaria. Así lo evidencia la referencia que hace a ella en el suplemento de la enciclopedia Espasa para los años 1936-39, «alabada unánimemente por los hispanistas ingleses, alemanes, italianos y americanos y por la crítica nacional, por la erudición y novedad de sus puntos de vista» (1944: 2.237). Referencia que culmina una cita de Juan Antonio de Zunzunegui al respecto, donde la considera «tal vez la que mejor historia hoy nuestras letras», y en relación al delicado tramo de lo más reciente señala que sus estudios sobre «las letras contemporáneas desde Unamuno hasta los poetas y prosistas del último momento, son de una justeza y un equilibrio perfectos». El texto debió entregarse a la editorial tiempo antes del indicado 1944 de su publicación, pues en la nómina de colaboradores del tomo el autor aún figuraba como catedrático de Barcelona.

Ángel Valbuena Prat permaneció en la Universidad de Murcia hasta 1964, cuando gana por oposición una cátedra en la Complutense, pero en realidad la pena impuesta en aquel lejano 1943 no se cumplió íntegra. Y es que su expediente fue revisado en 1946 y dictada orden ministerial el 28 de marzo de que «se considere depurado sin sanción alguna» (B. O. E. 15 de mayo). Por lo que hace al Gobierno franquista, este relato había concluido; sin embargo, la Historia de la literatura española, que el régimen había castigado como se ha visto, tenía todavía una larga trayectoria por delante. Precisamente ese mismo año 1946 vio la luz una segunda edición, claro que corregida y aumentada. Y con anterioridad a la muerte del profesor Valbuena seguirían seis ediciones más. En fin, la certificación más fehaciente de que estamos ante un clásico absoluto de la historiografía literaria en España, y no se olvide que junto al magnífico trabajo de Ángel del Río son las «historias de la literatura española» del grupo del 27, llega

\footnotetext{
${ }^{9}$ De los movimientos académico-burocráticos que median entre la propuesta de Gómez del Campillo de expulsar de su cátedra a Valbuena (8-10-1940) y la orden ministerial de 21 de enero del 43, que le envía a Murcia, no tenemos más noticia que una carta de Valbuena a Luis Ortiz Muñoz, Director General de Enseñanza Media, en la que se dice: «Le agradezco mucho su interés por mi asunto, y espero con impaciencia la solución de que hablamos a base de ir a la Universidad de Murcia. Le ruego no me olvide, pues deseo cuanto antes incorporarme al trabajo de cátedra, y creo que en Murcia encontraría muy buen ambiente, para dedicarme a la enseñanza con el entusiasmo de siempre» (25-12-1942).
} 
entre 1981 y 1983 cuando aparece la edición novena, póstuma, puesta al día por Antonio Prieto y María Pilar Palomo.

Ahora bien, antes de cerrar nuestro comentario y para vislumbrar los límites de la depuración a que fue sometido el libro de Valbuena en ese año 46, vale la pena echar un vistazo somero a cómo quedaron los aspectos censurados por el juez instructor en la $2^{\mathrm{a}}$ edición, ya rectificada. Evidentemente la nota al pie relacionada con Lorca queda como en el segundo estado de edición del 37, ponderando el influjo del granadino en Sanz y Ruiz de la Peña ${ }^{10}$. Felipe II sigue siendo un «monarca pálido y chiquito» (1946, II: 561), pero otros elementos en claroscuro del retrato que fragmenta Valbuena en su exposición se aclaran y convierten en rasgos más positivos: «fue más bien la parte menos honda y más oficial del momento: su religiosidad, aunque profunda, parece más rutinaria que creadora; y representó la burocracia, la observación meticulosa de los detalles» (562); y más concesiones se observan después:

Felipe II tuvo la preocupación de la moral y la justicia, aunque con cierta frialdad (...) Y no nos referimos al hacer esta pequeña salvedad, al exceso de celo en la represión religiosa, que constituyó durante mucho tiempo el blanco de las diatribas contra el rey (...) La leyenda negra está plenamente superada, y Antonio Pérez, que contribuyó a ella, es considerado hoy como un traidor nacional y adulador oportunista a la corte francesa. Con los hechos históricos, ajenos a la cuestión religiosa, hay suficiente para que el rey del rosario y el vestido negro tenga un cierto matiz diverso de la humanidad plena, en lo meditativo ascético de fray Luis y Montano. (576-7).

En cuanto al erasmismo, los perfiles de la redacción son más suaves, de forma que, por ejemplo, leemos: «Se comprende, por tanto, el erasmismo en tiempo de Carlos V, y también, la rica y segura adquisición de la reacción católica en el reinado siguiente» (401). Pero hay epígrafes de ese capítulo XVII que han cambiado un poco: los que primero eran «Alfonso de Valdés; su sátira de los abusos de la Iglesia» y «Juan de Valdés; su fina actividad religiosa», pasan a «Alfonso de Valdés; su sátira de los abusos; su parcialidad» y «Juan de Valdés; su actividad religiosa». Más llamativo aún es que el capítulo próximo deja de titularse «El erasmismo en el teatro», para convertirse en «El teatro renacentista de Naharro y Gil Vicente». Por su lado, no tan curiosamente como pudiese parecer a primera vista, el 98 cobra mayor presencia en la segunda edición, al conseguir tema propio Baroja, Azorín y Antonio Machado. Y por lo que respecta a lo más contemporáneo criticado, apenas si introduce Valbuena una mayor distancia respecto de la actividad literaria del Alberti comprometido.

\footnotetext{
${ }^{10}$ Tiene interés comprobar cómo queda dicha nota en la edición definitiva: «Creemos su fecha de nacimiento la indicada [1898], aunque algunos señalan la de1899. El lugar fue Fuente Vaqueros; sobre su trágica muerte, véase PEMÁN, artículo de $A B C$, 1948» (1968, IV: 648).
} 
La Historia de la literatura española de don Ángel Valbuena Prat en rigor no cambia tanto, más allá de los cambios de detalle obligados ante la violencia del régimen. Seguramente y como habrá de ratificar un cotejo en pormenor, la diferencia más notable entre aquella del 37 y la del 46 es la ampliación y no tanto la corrección de presuntos errores. Dicho de otro modo, la obra crece, se agranda, también en lo moral, porque no renuncia a su baza principal ante lo que significaba la dictadura, esto es, su deseo de construir la Historia con honestidad y capacidad de comprensión, con sensibilidad e inteligencia. Con respeto compatible con la posibilidad de discrepar. Razón le asistía a la profesora Palomo cuando observaba que «en Ángel Valbuena, creo que es imposible separar al hombre del crítico e historiador» (Palomo y Prieto, 2000: 22). El caso es que la Historia, quizá con sus estudios calderonianos y el poemario citado, son capítulos fundamentales de su autobiografía, la primera por encima de cualesquiera otros, porque, como él dijo en cierta ocasión y sin que supiese a ciencia cierta hasta qué punto predecía su futuro, el libro cuya historia parcial se ha reconstruido aquí fue «el trabajo de toda una vida». Por fortuna a la altura de 1946, el hombre y su Historia de la literatura española todavía tenían mucho que enseñar. Ahora, sin duda, también.

\section{BIBLIOGRAFÍA CITADA}

Alted Vigil, Alicia, 1991, «Bases político-ideológicas y jurídicas de la universidad franquista durante los ministerios de Sáinz Rodríguez y primera época de Ibáñez Martín (1938-1945)», en Carreras Ares y Ruiz Carnicer (1991), pp. 95-124.

Carreras Ares, Juan José (dir.) y Ruiz CARnicer, Miguel Ángel (coord.), 1991, La Universidad española bajo el régimen de Franco, Zaragoza, Institución Fernando el Católico.

DíEZ DE REvenga, Francisco Javier, 1977, «Recuerdo bibliográfico de Ángel Valbuena Prat», Monteagudo, 57, pp. 39-45.

—, 2000, «Valbuena Prat y los poetas de su generación», Monteagudo, 5, pp. 83-95.

Gracia García, Jordi, 2001, «La estética del miedo», en Gracia García y Ruiz Carnicer (2001), pp. 17-37.

- y Ruiz CARnicer, Miguel Ángel, 2001, La España de Franco (1939-1975) Cultura y vida cotidiana, Madrid, Síntesis.

Laín Entralgo, Pedro, 1989, Descargo de conciencia (1930-1960), Madrid, Alianza.

Nicolás MARín, María Encarna, 1991, «La universidad en los años cuarenta: Por una cultura unitaria y tradicional», en Carreras Ares y Ruiz Carnicer (1991), pp. 34170 .

NuEZ, Sebastián de la, 1978, «Ángel Valbuena Prat iniciador de la crítica y la historiografía modernas en la poesía canaria», Revista de Historia Canaria, 171, pp. 203-18.

Palomo, María del Pilar y Prieto, Antonio, 2000, «Historia de una Historia y evocación de Ángel Valbuena Prat», Monteagudo, 5, pp. 13-27.

Pozuelo Yvancos, José María, 2000, «Ángel Valbuena: La renovación de la historiografía literaria española», Monteagudo, 5, pp. 51-69.

Ruiz CARnicer, Miguel Ángel, 2001, «La cultura del poder. Propaganda en la alta manera», en Gracia García y Ruiz Carnicer (2001), pp. 155-85. 
Valbuena Prat, Ángel, 1937a, Historia de la literatura española (2 vols.), Barcelona, Gustavo Gili.

—, 1937b, Historia de la poesía canaria. Tomo I, Barcelona, Publicaciones del Seminario de Estudios Hispánicos.

—, 1939, Dios sobre la muerte. Poemas. Soliloquio a través de una vida 1914-1939 A. $V$. , Barcelona, Apolo.

—, 1940, El sentido católico en la literatura española, Zaragoza, Partenón.

-, 1944, «Literatura», en Enciclopedia Universal Ilustrada Europeo-Americana. Suplemento anual 1936-1939 (Segunda parte), Madrid, Espasa-Calpe, pp. 2.233-43 [firma A. V.]

—, 1946, Historia de la literatura española (2 vols.), $2^{\mathrm{a}}$ ed. corr. y aum., Barcelona, Gustavo Gili.

—, 1968, Historia de la literatura española (4 vols.), $8^{\mathrm{a}}$ ed. corr. y ampl., Barcelona, Gustavo Gili. 